\title{
THE JUNE MEETING IN MISSOULA
}

The six hundred forty-seventh meeting of the American Mathematical Society was held on Saturday, June 17, 1967 at the University of Montana, in Missoula, Montana, in conjunction with meetings of the Pacific Northwest Section of the Mathematical Association of America, the Institute for Mathematical Statistics, and the Society for Industrial and Applied Mathematics. There were 142 registrants at this meeting, 80 of whom were members of the Society.

By invitation of the Committee to Select Hour Speakers for Far Western Sectional Meetings, an hour address was given by Professor Leo Moser of the University of Alberta, Edmonton, Alberta. The title of his address was The second moment method in the theory of numbers. Professor Calvin Long introduced Professor Moser.

There were four sessions for contributed papers with Professors J. A. Carlson, Caspar Curjel, Heinrich Matzinger, and J. E. Whitesitt presiding.

Seattle, Washington

R. S. PIERCE

Associate Secretary 